\title{
Wnt3a: functions and implications in cancer
}

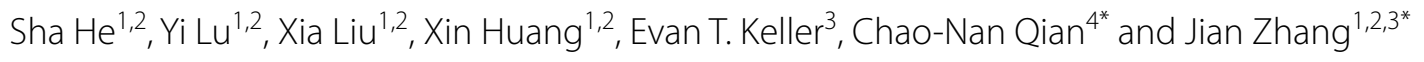

\begin{abstract}
Wnt3a, one of Wnt family members, plays key roles in regulating pleiotropic cellular functions, including self-renewal, proliferation, differentiation, and motility. Accumulating evidence has suggested that Wnt3a promotes or suppresses tumor progression via the canonical Wnt signaling pathway depending on cancer type. In addition, the roles of Wnt3a signaling can be inhibited by multiple proteins or chemicals. Herein, we summarize the latest findings on Wnt3a as an important therapeutic target in cancer.
\end{abstract}

Keywords: Wnt3a, The Wnt signaling pathway, Cancer

\section{Background: the Wnt signaling pathway}

The Wnt gene was first identified in 1982 and is named the Int gene in mice [1]. A subsequent study reported that the Int gene and wingless gene in Drosophila were homologous genes [2]. Therefore, both genes were recognized as the Wnt gene [3]. The Wnt family comprises 19 human proteins, including Wnt1, Wnt2, Wnt2b (Wnt13), Wnt3, Wnt3a, Wnt4, Wnt5a, Wnt5b, Wnt6, Wnt7a, Wnt7b, Wnt8a, Wnt8b, Wnt9a (Wnt14), Wnt9b (Wnt14b), Wnt10a, Wnt10b, Wnt11, and Wnt16. These genes encode secreted glycoproteins that are rich in cysteine [4]. Wnts can combine with cell membrane receptors that play a critical role in autocrine regulation and/or participate in paracrine modification by binding to adjacent cell membrane receptors. The signal transduction pathway mediated by Wnt genes is called the Wnt signaling pathway.

The Wnt signaling pathway can be divided into canonical and noncanonical pathways. The canonical pathway is also called the Wnt/ $\beta$-catenin pathway (Fig. 1). The noncanonical pathway includes the Wnt-planar

\footnotetext{
*Correspondence: qianchn@sysucc.org.cn; jianzhang008@hotmail.com

${ }^{3}$ Department of Urology and Pathology, School of Medicine, University of Michigan, Ann Arbor, MI 48109, USA

${ }^{4}$ Department of Nasopharyngeal Carcinoma, Sun Yat-sen University Cancer Center, State Key Laboratory of Oncology in South China, Collaborative Innovation Center of Cancer Medicine, Guangzhou, Guangdong 51006, P.R. China

Full list of author information is available at the end of the article
}

cell polarity pathway (Wnt-PCP pathway) and the Wntcalcium pathway (Wnt-Ca ${ }^{2+}$ pathway) [5]. According to the characteristics of its functions, the Wnt family can also be divided into two categories: Wnt1 and Wnt5a. The Wnt1 category includes Wnt1, Wnt2, Wnt2b, Wnt3, Wnt3a, Wnt7a, Wnt8, Wnt8b, and Wnt10a, which are involved in the canonical signaling pathway, whereas Wnt4, Wnt5a, and Wnt11 belong to the Wnt5a category and activate the noncanonical signaling pathway.

The canonical Wnt pathway begins with the binding of a Wnt ligand to its receptor Frizzled (Fz) and co-receptor lipoprotein receptor-related protein (LRP5/6), which then activates the scaffold protein Disheveled (Dvl) and causes dissociation of the "destruction complex" formed with casein kinase 1 (CK1), glycogen synthase kinase-3 $\beta$ (GSK-3 $\beta$ ), and the scaffolding proteins adenomatous polyposis coli (APC), Axin1, and Axin2 [6, 7]. The dissociation of the "destruction complex" causes degradation of $\beta$-catenin, therefore inducing the cytoplasmic accumulation of $\beta$-catenin and its translocation into the nucleus to interact with $\mathrm{T}$ cell-specific transcription factor (TCF) and lymphoid enhancer-binding factor (LEF), which regulate the expression of Wnt target genes $[6$, 7]. The $\mathrm{Wnt} / \beta$-catenin signaling pathway is one of the most conserved pathways in organism evolution and plays key roles in embryonic development, cell growth, differentiation, polarity formation, neural development, and carcinogenesis [8]. Aberrant activation of the Wnt/ $\beta$-catenin signaling pathway has been implicated in 


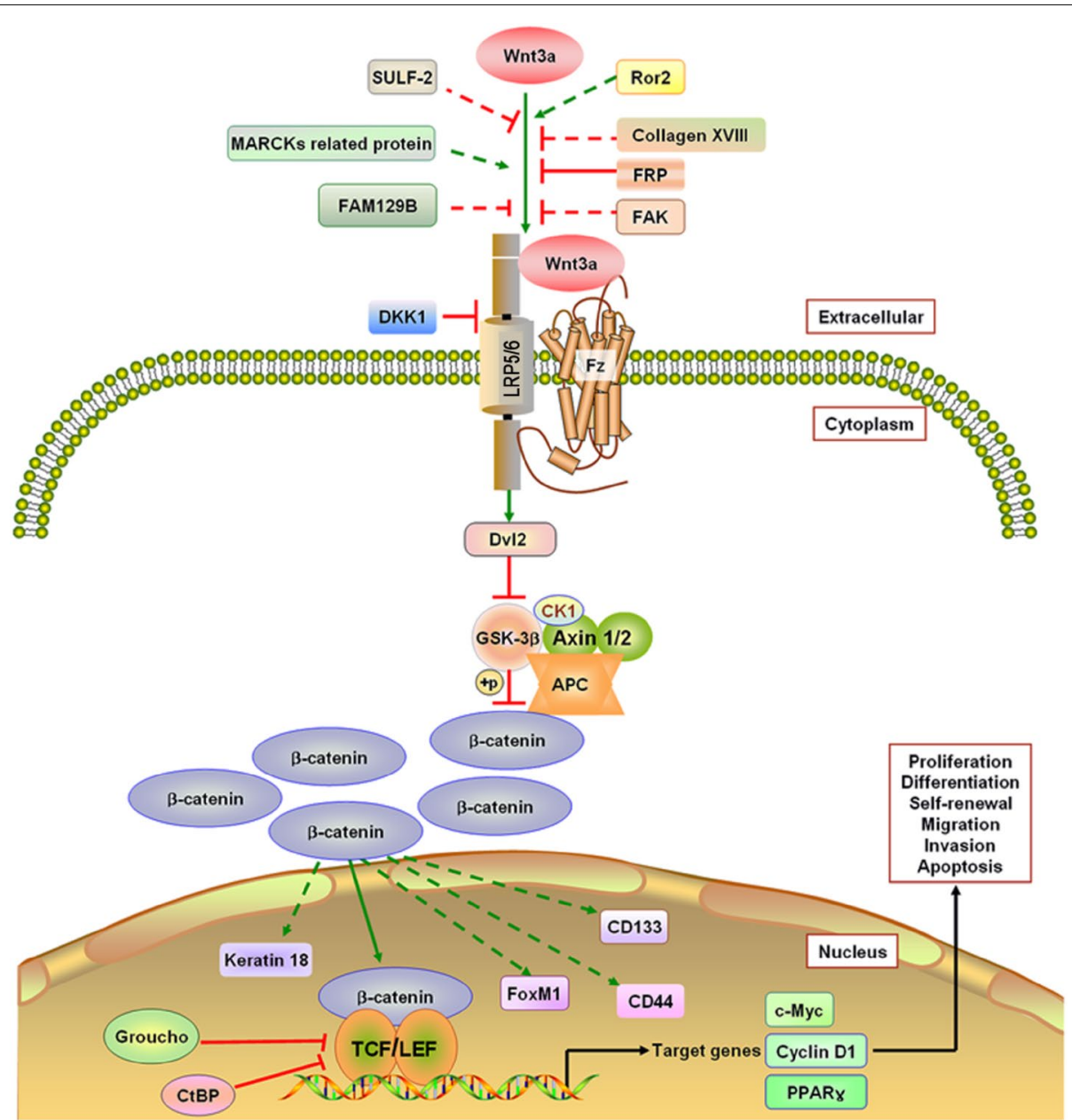

Fig. 1 The canonical Wnt3a pathway. SULF-2 sulfatase 2, Ror2 an orphan receptor, belonging to the Ror family of receptor tyrosine kinases, MARCKS myristoylated alanine-rich C-kinase substrate, FAM129B family with sequence similarity 129, member B, FAK focal adhesion kinase, DKK1 Dickkopf-

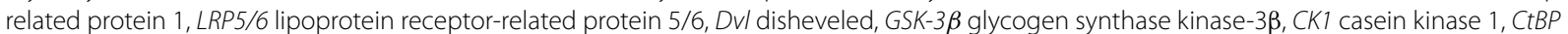
C-terminal binding protein, PPAR $\gamma$ peroxisome proliferator-activated receptor-gamma, TCFT-cell-specific transcription factor, LEF lymphoid enhancer-binding factor, FRP frizzled-related protein, Axin $1 / 2$ axis inhibition protein 1 and 2, APC adenomatous polyposis coli, FoxM1 forkhead box M1

a wide variety of cancer types $[9,10]$, and $\beta$-catenin has been demonstrated to be a crucial factor for regulation of Wnt/ $\beta$-catenin downstream target genes [9]. Nuclear accumulation of $\beta$-catenin has been recognized as a biomarker for cancer prognosis $[11,12]$.

\section{Wnt3a in non-cancer cell development}

The Wnt3a gene, clustered on human chromosome 1q42 [13], induces the accumulation of $\beta$-catenin, thereby activating the canonical Wnt signaling pathway [14]. It plays crucial roles in both proliferation and differentiation processes in several types of stem cells, such as neural stem cells and hematopoietic stem cells. In addition, Wnt3a can stimulate the migration and invasion of trophoblasts [15] and induce the survival, proliferation, and migration of human embryonic kidney (HEK) 293 cells [16]. Wnt3a has also been shown to induce the migration, invasion, and colony formation of mouse mammary epithelial HC11 cells [17]. In addition, Wnt3a can down-regulate E-cadherin expression and increase the proliferative potency of ovarian surface epithelium (OSE) cells [18]. Wnt3a promotes cell survival and the formation of spheroids in colonic epithelial cells or crypts [19] and inhibits apoptosis in mouse embryonic liver stem cells, prolonging their survival by up-regulating anti-apoptotic factors and down-regulating pro-apoptotic factors of the Bcl-2 family [20]. Wnt3a up-regulates genes implicated in melanocyte differentiation [21] and increases the expression and nuclear localization of the transcriptional co-activator with PDZ-binding motif (TAZ), a transcriptional 
modulator that plays a key role in cell proliferation, differentiation, and stem cell self-renewal, activating osteoblastic differentiation [22]. This process also induces osteoblastic differentiation and the expression of osteoprotegerin (OPG) in osteoblast precursor $\mathrm{C} 2 \mathrm{C} 12$ cells [23]. Furthermore, Wnt3a inhibits B lymphopoiesis and plasmacytoid dendritic cells but promotes the retention of hematopoietic stem cell markers, cell yields [24], and the self-renewal of hematopoietic stem cells [25]. Wnt3a suppresses the differentiation of mesenchymal stem cells into osteogenic or adipogenic lineages and Wnt3a-producing TW3R feeder cells, providing a growth advantage for undifferentiated human induced pluripotent stem cells (iPSC) and embryonic stem cells (ESCs) [26]. Wnt3a promotes the proliferation of human ESCs [27]. Wnt3a induces cell proliferation, morphological changes, and migration in C18-4 spermatogonial stem cells, and it maintains adult human embryonic stem (ES)-like cells derived from human germ cells in an undifferentiated stage, expressing essential human ES cell transcription factors [28]. Co-culture of Wnt3a-producing rat embryonic fibroblasts with human pre-B leukemia cell lines KM3 and REH significantly reduces Apo2L/TNF-related apoptosis-inducing ligand (TRAIL)-induced apoptosis of the lymphoid cells [29]. Wnt3a expression leads to stabilization and nuclear accumulation of $\beta$-catenin in primary lineage-restricted $B$ progenitor cells, suppresses $B$ lymphopoiesis of $\mathrm{CD} 133^{+} \mathrm{CD} 10^{-}$hematopoietic progenitor cells and $\mathrm{CD} 10^{+} \mathrm{B}$ progenitor cells, and suppresses cell division of $\mathrm{B}$ progenitor cells [30]. Wnt3a promotes ${\mathrm{c}-\mathrm{Kit}^{-}}^{-}$cells to induce myeloid and erythroid progenitors with robust self-renewal capacity. Wnt3a-stimulated

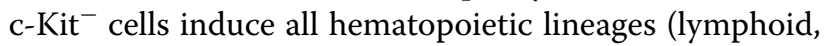
myeloid, and erythroid) upon transplantation into the liver of newborn recipient mice [31].

Wnt3a also plays important roles in organ formation. It can enhance cardiac myogenesis by increasing TCFdependent transcription and inducing cardiac-specific markers, bone morphogenetic proteins (BMPs), and sarcomeric myosin heavy chains (MHC) [32]. Wnt3a has been shown to induce myogenesis in the myotome of the differentiating somite and the activation of myogenic differentiation antigen (MyoD) expression and subsequent skeletal muscle development [33].

Wnt3a actives atypical protein kinase C ioys (pKCiota) and induces a punctate distribution of pKCiota in the neurites and cytoplasm, with a particularly intense signal at the centrosome [34]. Wnt3a serves as a crucial player in neuro-mesodermal stem cell maintenance and differentiation [35]. Therefore, Wnt3a is involved in the formation of the nervous system.

It has been reported that Wnt3a induces production of bone-protective OPG and alkaline phosphates in preosteoblastic $\mathrm{C} 2 \mathrm{C} 12$ cells [36]. It can also induce natural killer $\mathrm{T}$ cell anergy to re-stimulate alpha-GalCer [37]. Wnt3a prevents the adverse effects of Lgr4 loss on organoid formation [38] and induces EphB4 in mesenchymal stem cells [39]. Wnt3a increases the percentage of $\mathrm{CD}_{4} 4^{-} \mathrm{CD} 7^{+}$and $\mathrm{CD}^{-} 4^{-} \mathrm{CD}^{+}{ }^{+} \mathrm{CyCD}^{+}$cells and the expression of CD3 epsilon and preT alpha [40]. Wnt3a overexpression is positively associated with ulcerative colitis versus noninflammatory bowel disease [41]. Wnt3a induced Fz1 expression in a normal colon mucosa-derived cell line in vitro [42]. It has been demonstrated that Wnt3a mediates somitogenesis by activating a network of interacting target genes that promote mesodermal fate and position boundary determination genes, thus activating the segmentation clock in the anterior presomitic mesoderm [35].

\section{Wnt3a expression in tumors}

Tumor development depends upon the interactions among environmental factors, cells in the tumor microenvironment, and the genetic nature of tumor cells, leading to the disordered expression of oncogenes, tumor suppressor genes, and abnormal intracellular signal transduction pathways. Studies on intracellular signal transductions have become "hot" research fields in terms of tumorigenesis, invasion, and metastasis. Abnormal activation of the Wnt signaling pathway has been shown to be closely associated with tumor progression and be involved in various types of cancer. For example, Wnt3a is highly expressed in human scirrhous gastric carcinoma 44As3 cells with highly metastatic derivatives [43], advanced prostate cancer cells [44], and activating transcription factor (ATF3)-induced mammary tumors [45]. Wnt3a expression is higher in most breast cancer cell lines than in normal human mammary epithelial cells [46], which is also true in oral squamous cell carcinoma compared with control nonmalignant tissues [47]. In addition, Wnt3a expression is associated with the clinical grade and aggressiveness of gliomas, and interestingly, it is overexpressed on glioma stem cells [48]. Wnt3a and Wnt3 mRNA were reported to be co-expressed in the embryonal carcinoma NT2 cell line and the breast cancer MCF-7 cell line [49].

\section{Wnt3a suppresses or promotes cancer cell growth in vitro}

Wnt3a can either suppress or promote cancer cell growth, depending upon cancer types. For example, Wnt3a suppresses the growth and proliferation of the lung and lacrimal gland [50], induces B-cell precursor acute lymphoblastic leukemia (B-ALL) cell death [51], and suppresses the proliferation of several B-ALL cell lines [52]. Wnt3a enhances TRAIL-dependent apoptosis in multiple 
melanoma cell lines [53]. Wnt3a decreases proliferation rate and induces myogenic differentiation in alveolar rhabdomyosarcoma cells [54]. On the other hand, Wnt3a antagonizes the inhibition of the self-renewal of liver cancer stem cells induced by 8-bromo-7-methoxychry [55], promotes the self-renewal of leukemic stem/progenitor cells in some acute myeloid leukemia and acute T-lymphoblastic leukemia cell lines [25], promotes the proliferation and survival of acute lymphoblastic leukemia cells [56], reduces the anti-proliferative activity of lenalidomide multiple myeloma [57], and stimulates the proliferation of malignant mesothelioma cells [58]. Moreover, Wnt3a promotes the proliferation of breast cancer MCF7 cells [59] and increases the expression of highmobility group A protein 1 to maintain the proliferation of gastric cancer cells [60]. Wnt3a reverses docosahexaenoic acid-induced growth inhibition in human pancreatic cancer PANC-1 cells [61]. Increased Wnt3a expression induces prostate cancer LNCaP cell proliferation, neutralizing antibodies to reverse Wnt3a tumorigenesis [62]. Wnt3a can enhance hypoxia-induced epithelial-mesenchymal transition (EMT) in hepatocellular carcinoma (HCC) [63]. Wnt3a may play a key role in the maintenance of NT2 cells in the undifferentiated proliferation stage [49]. When $4 \mathrm{~T} 1$ cells are treated with recombinant Wnt3a along with quercetin, Wnt3a is able to restore the suppressed cell viability by quercetin [64]. Furthermore, Wnt3a treatment significantly decreases the drug susceptibility of cholangiocarcinoma QBC939 cells to common chemotherapeutics [65], sensitizes malignant mesothelioma cells to cytotoxic drugs [58], and induces striking morphological changes accompanied by the rearrangement of the actin cytoskeleton in myeloma cells [66].

\section{Wnt3a affects tumor growth in vivo}

It has been reported that based on the expression of Wnt3a, erb-b2 receptor tyrosine kinase 3 (ERBB3), lymphocyte-specific protein tyrosine kinase $(L C K)$, and Rho family GTPase 3 (RND3) to predict mortality, the fourgene model achieved better predictive value than clinical stage or tumor size in early-stage non-small cell lung cancer [67]. Wnt3a decreases metastases in a mouse melanoma model [68]. However, the Wnt3a transduced into HCC cells may promote cell cycle progression and accelerate tumor formation in athymic nude mice [69]. Co-injecting Wnt3a-expressing human mammary fibroblasts with human breast cancer cell lines into mouse mammary fat pads accelerates tumor growth [70]. Wnt3a treatment abolishes sorafenib-induced HCC growth inhibition in vitro and in vivo [71]. Wnt3a-expressing H929 cells injected into human bone exhibit increased osteoblast-to-osteoclast ratios and therefore reduce tumor burden. Likewise, treatment with recombinant Wnt3a stimulates bone formation and attenuates multiple myeloma cell growth in myelomatous severe combined immunodeficiency (SCID)-hu mice [72].

\section{Wnt3a functions in cancer \\ Wnt3a modulates gene expression in cancer}

The apoptosis signal-regulating kinase 1 (ASK1) protein expression level is reduced in L929 cells that stably express Wnt3a versus L929 control cells [73]. Wnt3a causes increased self-renewal and prostasphere size, which is associated with a significant increase in nuclear $\beta$-catenin, keratin 18, CD133, and CD44 expression in prostate cancer cells [74]. Wnt3a increases the level of forkhead box M1 (FoxM1), which binds directly to $\beta$-catenin, enhancing $\beta$-catenin nuclear localization and transcriptional activity in tumor cells [75], and increases prostaglandin E2 (PGE2) levels through very early 15-hydroxyprostaglandin dehydrogenase (15-PGDH) suppression to promote colorectal tumorigenesis [76]. Wnt3a can enhance the expression and activity of phospholipase D1 (PLD1; a cell survival mediator) in many types of cancer cells [77] and enhance the expression of PLDs at a transcriptional level, as shown in colorectal cancer HCT116 cells. PLD is necessary for the Wnt3adriven invasion and anchorage-independent growth of colon cancer cells [78]. Wnt3a induces BMP-4 and BMP-6 expression and their promoter activation in prostate cancer cells [79]. It significantly increases junction plakoglobin, interacts with sex-determining region Y-related high-mobility group box 4 (SOX4) in both the cytosol and the nucleus, and enhances the interaction between SOX4 and plakoglobin in prostate and breast cancer cells [80]. In prostate cells, Wnt3a can recruit the androgen receptor (AR) to the promoter regions of c-Myc and cyclin D1 [81]. Wnt3a either induces AR activity in the absence of androgen or enhances AR activity in the presence of low concentrations of androgen, and significantly enhances growth of $\mathrm{LNCaP}$ cells in the absence of androgen [82]. Wnt3a expression is significantly associated with lymph node involvement and matrix metallopeptidase-9 (MMP-9) expression in primary tumor, mesenchyme adjacent to tumor, and metastatic sites in colorectal cancer [83]. It has been reported that the expression of the Wnt pathway genes is associated with estrogen receptor (ER) expression, and specific Wnt genes can predict relapse within specific subtypes of breast cancer. Wnt3a can increase mammosphere formation in ER-positive breast cancer cell lines; however, only ER-negative mammospheres are responsive to the ligand Wnt3a in patient-derived metastatic breast cancer samples [84]. 
Wnt3a is regulated by genes/proteins in cancer

Sulfatase 2 (SULF2) increases Wnt3a expression in HCC cells, and xenografts established from SULF2-transfected Hep3B cells show increased Wnt3a levels in nude mice [85]. Dvl2 may increase prostate cancer growth and metastatic potential by up-regulating Wnt3a expression [86]. Ror2 positively modulates the Wnt3a-activated canonical Wnt signaling pathway in lung carcinoma H441 cells [87].

\section{Potential inhibitors of Wnt3a signaling in preclinical studies}

Increasing evidence has demonstrated that a number of proteins and chemicals can inhibit Wnt3a signaling in vitro and in vivo (Table 1).

\section{Proteins}

Knockdown of myristoylated alanine-rich C-kinase substrate (MARCKS)-related protein in EpRas mammary epithelial cells reduces Wnt3a-induced TCF reporter signaling in vitro and causes loss of tumorigenesis in vivo [88]. Variant 3 of Collagen XVIII suppresses Wnt3a-induced stabilization of $\beta$-catenin and then down-regulates cyclin D1 and c-Myc to reduce tumor cell growth in colorectal and liver cancer cell lines [89]. Dickkopf-related protein 1 (DKK1) inhibits the Wnt3aregulated OPG and receptor activator of NF-kappaB ligand (RANKL) expression in osteoblasts, indirectly inducing osteoclast function [72, 90, 91]. DKK1 blocks Wnt3a-induced $\beta$-catenin accumulation in multiple

Table 1 Potential inhibitors of Wnt3a

\begin{tabular}{|c|c|c|c|}
\hline Tissue type & Cell line(s) & Potential inhibitor(s) of Wnt3a & Reference(s) \\
\hline Breast cancer & $\begin{array}{l}\text { EpRas } \\
\text { MDA-MB-231, T-47D } \\
\text { MDA-MB-231 } \\
\text { MCF-7 }\end{array}$ & $\begin{array}{l}\text { Knockdown of MARCKS-related protein } \\
\text { Niclosamide and silibinin } \\
\text { Kallistatin } \\
\text { Deep-sea water } \\
\beta \text {-estradiol } \\
\text { Knockdown of FAK protein }\end{array}$ & $\begin{array}{l}{[88]} \\
{[111,112]} \\
{[99]} \\
{[114]} \\
{[49]} \\
{[95]}\end{array}$ \\
\hline Colon cancer & SW480 & MEK inhibitor PD98059, genistein, and wortmannin & {$[100]$} \\
\hline Gastric cancer & Gastric cancer cells & Receptor for activated protein kinase $C$ & {$[103]$} \\
\hline Leukemia & U937 & Cordycepin & {$[107]$} \\
\hline Liver cancer & Huh-7 & $\begin{array}{l}\text { Variant } 3 \text { of collagen XVIII } \\
\text { HS20 }\end{array}$ & $\begin{array}{l}{[89]} \\
{[96]}\end{array}$ \\
\hline Multiple myeloma & OPM-2, and MM patients' plasma cells & DKK1 & {$[92]$} \\
\hline Melanoma & A375 and A2058 & Loss of FAM129B & {$[94]$} \\
\hline Prostate cancer & $\begin{array}{l}\text { C4-2B } \\
\text { PC-3 and DU145 }\end{array}$ & $\begin{array}{l}\text { Axin } \\
\text { Niclosamide and silibinin }\end{array}$ & $\begin{array}{l}{[79]} \\
{[111,112]}\end{array}$ \\
\hline Renal carcinoma & $\mathrm{ACHN}$ & Enhancer of zeste homolog 2 small interfering RNA & [93] \\
\hline Teratocarcinoma & $\begin{array}{l}\text { F9 } \\
\text { NT2 }\end{array}$ & $\begin{array}{l}\text { RGS19 } \\
\text { All-trans-retinoic acid }\end{array}$ & $\begin{array}{l}{[104]} \\
{[115]}\end{array}$ \\
\hline HEK293 & HEK293 & $\begin{array}{l}\text { Etinoic acid } \\
\text { Variant } 3 \text { of collagen XVIII } \\
\text { Purified recombinant frizzled cysteine-rich domain } \\
\text { MEK inhibitor PD98059, genistein, and wortmannin } \\
\text { Aspirin and norcantharidin } \\
\text { Hexachlorophene } \\
\text { Demethoxycurcumin and bisdemethoxycurcumin } \\
\text { Mesd C-terminal region peptide and full-length Mesd protein } \\
\text { A diterpenoid derivative, 15-oxospiramilactone } \\
\text { Niclosamide and silibinin } \\
\text { Magnolo I }\end{array}$ & $\begin{array}{l}{[49]} \\
{[89]} \\
{[98]} \\
{[100]} \\
{[108]} \\
{[109]} \\
{[110]} \\
{[105]} \\
{[106]} \\
{[111,112]} \\
{[116]}\end{array}$ \\
\hline Embryos & $\begin{array}{l}\text { Cytotrophoblasts } \\
\text { Neural plate }\end{array}$ & $\begin{array}{l}\text { DKK1 } \\
\text { Knockdown of FAK }\end{array}$ & $\begin{array}{l}{[15]} \\
{[95]}\end{array}$ \\
\hline B lymphopoiesis & $\mathrm{CD}_{133^{+} \mathrm{CD} 10^{-} \mathrm{CD} 0^{+} \text {cells }}$ & DKK1 & {$[30]$} \\
\hline Fibroblasts & $\mathrm{NIH} 3 \mathrm{T3}$ & Chondroitin sulfate-E & {$[97]$} \\
\hline $\begin{array}{l}\text { Osteoblasts } \\
\text { Osteoblast-like cells }\end{array}$ & $\begin{array}{l}\text { Osteoblasts } \\
\text { Saos-2, MG63, C2C12, and hFOB1.19 } \\
\text { C2C12 }\end{array}$ & $\begin{array}{l}\text { DKK1 } \\
\text { DKK1 } \\
\text { Mesd C-terminal region peptide }\end{array}$ & $\begin{array}{l}{[90]} \\
{[91,92]} \\
{[105]}\end{array}$ \\
\hline
\end{tabular}

MARCKS myristoylated alanine-rich C-kinase substrate, FAK focal adhesion kinase, MEK mitogen activated and extracellular regulated kinase, $H S 20$ a human monoclonal antibody against GPC3, GPC3 glypican-3, DKK1 Dickkopf-related protein 1, FAM129B family with sequence similarity 129 , member B, RGS19 regulator of G-protein signaling 19 
myeloma [92] and Wnt3a-mediated B lymphopoiesis of $\mathrm{CD} 133^{+} \mathrm{CD} 10^{-}$hematopoietic progenitor cells and $\mathrm{CD} 10^{+} \mathrm{B}$ progenitor cells [30]. Pre-treatment with recombinant DKK1 completely abolishes Wnt3a-induced OPG expression in mouse and human osteoblasts. Wnt3a-induced OPG expression could be diminished in osteoblasts co-cultured with a DKK1-expressing multiple myeloma (MM) cell line or primary MM cells. DKK1 blocks Wnt3a-stimulated trophoblast migration and invasion through matrigel and also reduces basal migration, invasion, and proliferation of cytotrophoblasts [15]. The enhancer of zeste homolog 2 small interfering RNA reduces the expression of Wnt3a and $\beta$-catenin in renal cell carcinoma and markedly inhibits the proliferation and invasion capabilities of human renal carcinoma ACHN cells [93]. FAM129B is needed for Wnt3a to activate a $\beta$-catenin-dependent reporter and decreases the ability of Wnt3a to increase the expression of the $\beta$-catenin target gene Axin2. Loss of FAM129B inhibited the apoptosis of melanoma cells induced by Wnt3a [94]. Knockdown of focal adhesion kinase (FAK) downregulates Wnt3a gene expression in the neural plate [95]. HS20, a human monoclonal antibody against glypican-3 (GPC3), blocks Wnt3a/ $\beta$-catenin signaling. Moreover, HS20 inhibits Wnt3a-dependent cell proliferation in vitro and HCC xenograft growth in nude mice [96]. Chondroitin sulfate-E decreases Wnt3a signaling through the negative regulation of LRP6 receptor activation in NIH3T3 fibroblasts [97]. Purified recombinant frizzled cysteinerich domain inhibits Wnt3a-induced $\beta$-catenin activation in vitro [98]. Kallistatin inhibits the Wnt3a-induced proliferation, migration, and invasion of breast cancer cells. Furthermore, kallistatin suppresses the Wnt3a-mediated phosphorylation of LRP6 and GSK-3 $\beta$ and the elevation of cytosolic $\beta$-catenin levels. Kallistatin has been shown to antagonize the expression of Wnt3a-induced target genes, including $c-M y c$, cyclin D1, and vascular endothelial growth factor (VEGF) [99]. The mitogen activated and extracellular regulated kinase (MEK) inhibitor PD98059, genistein, and wortmannin effectively suppress Wnt3a/ $\beta$-catenin-regulated transcriptional activities as well as the intracellular accumulation of $\beta$-catenin protein in human colon cancer cells [100]. Axin blocks Wnt3a's induction of BMP promoters in prostate cancer $\mathrm{C} 4-2 \mathrm{~B}$ cells [79]. Small interfering RNA of LRP5/6, secreted frizzled-related protein 2 (sFRP2), or sFRP5 potently reduce Wnt3a-mediated $\beta$-catenin accumulation [101]. The protein kinase N1 inhibits Wnt/ $\beta$-catenin signaling and sensitizes melanoma cells to cell death stimulated by Wnt3a [102]. The receptor for activated protein kinase C inhibits Wnt3a signaling by inhibiting the recruitment of Axin by Dvl 2 and by stabilizing the $\beta$-catenin destruction complex and acts as a tumor suppressor in gastric cancer cells [103]. Regulator of G-protein signaling 19 (RGS19) specifically reduces Wnt-responsive gene transcription in time-dependent and dose-dependent manners and blocks Wnt3a-induced cytosolic $\beta$-catenin accumulation, Dvl3 phosphorylation, and the formation of primitive endoderm [104]. The Mesd C-terminal region peptide and the full-length Mesd protein block Wnt3a-induced $W n t / \beta$-catenin signaling in LRP5- and LRP6-expressing cells, inhibit $W n t / \beta$-catenin signaling in human breast HS578T cells and prostate cancer PC-3 cells, and inhibit cancer cell proliferation [105].

\section{Chemicals}

The diterpenoid derivative 15-oxospiramilactone suppresses Wnt3a-stimulated top-flash reporter activity in HEK293T cells and inhibits the growth of colon cancer SW480 and Caco-2 cells [106]. Cordycepin suppresses the effect of Wnt3a-induced $\beta$-catenin in leukemia cells [107]. Norcantharidin reduces $80 \%$ of Wnt3a-induced $\beta$-catenin binding with lymphoid enhancer factor/T-cell factor protein [108]. Hexachlorophene antagonizes the Wnt3a-induced $\beta$-catenin response transcription (CRT) by promoting the degradation of $\beta$-catenin. In addition, hexachlorophene represses the expression of cyclin D1 and inhibits the growth of colon cancer cells [109]. Demethoxycurcumin and bisdemethoxycurcumin suppress $\beta$-catenin transcription activated by Wnt3a-conditioned medium and inhibit the growth of various colon cancer cells [110]. Niclosamide and silibinin inhibit LRP6 expression and phosphorylation, block Wnt3a-induced $\beta$-catenin accumulation, and inhibit Wnt/ $\beta$-catenin signaling in HEK293 cells, prostate cancer PC-3 and DU145 cells, and breast cancer MDA-MB-231 and T-47D cells $[111,112]$. Verapamil improves Wnt3a-induced loss of proteoglycan in chondrogenically differentiated ATDC5 cells [113].

Furthermore, retinoic acid can reduce Wnt3a mRNA expression in NT2 cells. Wnt3a expression is downregulated by $\beta$-estradiol in MCF-7 cells [49]. Deep-sea water treatment results in a concomitant decrease in mRNA levels of MMP-9, transforming growth factor- $\beta$ $(T G F-\beta), W n t 5 a$, and Wnt3a in human breast cancer MDA-MB-231 cells [114]. All-trans-retinoic acid downregulates the expression of Wnt3a, Wnt8a, Wnt8b, Wnt10b, and Wn11 in NT2 cells [115]. Magnolol inhibits Wnt3a-induced $\beta$-catenin translocation and subsequent target gene expression in human embryonic kidney 293 cells [116].

\section{Conclusions}

Wnt3a, an important member of the Wnt family, activates the canonical Wnt signaling pathway to exhibit its biological functions. It is mainly involved in embryonic 
development, neural development, cell differentiation, proliferation, and tumorigenesis. Overall, our understanding of Wnt3a is incomplete, and molecular mechanisms of its specific roles remain to be further studied in various diseases, including cancer.

\section{Authors' contributions}

$\mathrm{SH}, \mathrm{YL}$, and $\mathrm{XL}$ designed and wrote the manuscript; $\mathrm{XH}$ and EK revised the manuscript; CQ and JZ co-designed, reviewed, and revised the manuscript. All authors read and approved the final manuscript.

\section{Author details}

1 Key Laboratory of Longevity and Ageing-related Diseases, Ministry of Education, Nanning, Guangxi 530021, P.R. China. ${ }^{2}$ Center for Translational Medicine, Guangxi Medical University, Nanning, Guangxi 530021, P.R. China. ${ }^{3}$ Department of Urology and Pathology, School of Medicine, University of Michigan, Ann Arbor, MI 48109, USA. ${ }^{4}$ Department of Nasopharyngeal Carcinoma, Sun Yat-sen University Cancer Center, State Key Laboratory of Oncology in South China, Collaborative Innovation Center of Cancer Medicine, Guangzhou, Guangdong 51006, P.R. China.

\section{Acknowledgements}

This work was supported by National Natural Science Foundation of China (NSFC) Key Project (81130046 to JZ), NSFC projects (81171993 and 81272415 to $\mathrm{YL}$, and 81272340 and 81472386 to CNQ), National Natural Science Foundation of Guangxi Key Projects (2013GXNSFEA053004 to JZ and 2012GXNSFCB053004 to YL), Guangxi Projects (1355004-5 to JZ), and Guangxi Ministry of Education (201202ZD022 to YL and 201201ZD004 to JZ). The authors thank Drs. Jie-Jun Fu and Chun-Lin Zou for helpful discussions and Ms. Xiao-Lin Zhou for editing.

\section{Compliance with ethical guidelines}

\section{Competing interests}

The authors declare that they have no competing interests.

Received: 10 April 2015 Accepted: 18 August 2015

Published online: 14 September 2015

\section{References}

1. Nusse R, Varmus HE. Many tumors induced by the mouse mammary tumor virus contain a provirus integrated in the same region of the host genome. Cell. 1982;31(1):99-109.

2. Nusse R, Varmus H. Three decades of Wnts: a personal perspective on how a scientific field developed. EMBO J. 2012;31(12):2670-84.

3. Cadigan KM, Nusse R. Wnt signaling: a common theme in animal development. Genes Dev. 1997;11(24):3286-305.

4. Bodine PV. Wnt signaling control of bone cell apoptosis. Cell Res. 2008;18(2):248-53.

5. Wang Y, Li YP, Paulson C, Shao JZ, Zhang X, Wu M, et al. Wnt and the Wnt signaling pathway in bone development and disease. Front Biosci (Landmark Ed). 2014;19:379-407.

6. Tran H, Bustos D, Yeh R, Rubinfeld B, Lam C, Shriver S, et al. HectD1 E3 ligase modifies adenomatous polyposis coli (APC) with polyubiquitin to promote the APC-axin interaction. J Biol Chem. 2013;288(6):3753-67.

7. Clevers H, Nusse R. Wnt/beta-catenin signaling and disease. Cell. 2012;149(6):1192-205

8. Wang L, Li H, Chen Q, Zhu T, Zhu H, Zheng L. Wnt signaling stabilizes the DIXDC1 protein through decreased ubiquitin-dependent degradation. Cancer Sci. 2010;101(3):700-6.

9. Chan DW, Mak CS, Leung TH, Chan KK, Ngan HY. Down-regulation of Sox7 is associated with aberrant activation of Wnt/b-catenin signaling in endometrial cancer. Oncotarget. 2012;3(12):1546-56.

10. Yang JL. Investigation of osteosarcoma genomics and its impact on targeted therapy: an international collaboration to conquer human osteosarcoma. Chin J Cancer. 2014;33(12):575-80.
11. Chocarro-Calvo A, Garcia-Martinez JM, Ardila-Gonzalez S, De la Vieja A, Garcia-Jimenez C. Glucose-induced beta-catenin acetylation enhances Wnt signaling in cancer. Mol Cell. 2013;49(3):474-86.

12. Valkenburg KC, Steensma MR, Williams BO, Zhong Z. Skeletal metastasis: treatments, mouse models, and the Wnt signaling. Chin J Cancer. 2013;32(7):380-96.

13. Kirikoshi H, Sekihara H, Katoh M. Expression of WNT14 and WNT14B mRNAs in human cancer, up-regulation of WNT14 by IFNgamma and up-regulation of WNT14B by beta-estradiol. Int J Oncol. 2001;19(6):1221-5.

14. Katoh M. Comparative genomics on Wnt8a and Wnt8b genes. Int J Oncol. 2005;26(4):1129-33.

15. Pollheimer J, Loregger T, Sonderegger S, Saleh L, Bauer S, Bilban M, et al. Activation of the canonical wingless/ $T$-cell factor signaling pathway promotes invasive differentiation of human trophoblast. Am J Pathol. 2006;168(4):1134-47.

16. Gujral TS, MacBeath G. A system-wide investigation of the dynamics of Wnt signaling reveals novel phases of transcriptional regulation. PLoS One. 2010;5(4):e10024.

17. Nagaoka T, Karasawa H, Turbyville T, Rangel MC, Castro NP, Gonzales $M$, et al. Cripto-1 enhances the canonical Wnt/beta-catenin signaling pathway by binding to LRP5 and LRP6 co-receptors. Cell Signal. 2013;25(1):178-89.

18. Usongo M, Li X, Farookhi R. Activation of the canonical WNT signaling pathway promotes ovarian surface epithelial proliferation without inducing beta-catenin/Tcf-mediated reporter expression. Dev Dyn. 2013;242(3):291-300.

19. Hirokawa Y, Yip KH, Tan CW, Burgess AW. Colonic myofibroblast cell line stimulates colonoid formation. Am J Physiol Gastrointest Liver Physiol. 2014;306(7):G547-56.

20. Zhang X, Hu D, Lu Y, Feng T, Huang J. Overexpression of Wnt3a inhibited the apoptosis of mouse embryonic liver stem cells. Xi Bao Yu Fen Zi Mian Yi Xue Za Zhi. 2013;29(12):1277-80 (in Chinese).

21. Chien AJ, Moore EC, Lonsdorf AS, Kulikauskas RM, Rothberg BG, Berger $\mathrm{AJ}$, et al. Activated Wnt/beta-catenin signaling in melanoma is associated with decreased proliferation in patient tumors and a murine melanoma model. Proc Natl Acad Sci USA. 2009;106(4):1193-8.

22. Byun MR, Hwang JH, Kim AR, Kim KM, Hwang ES, Yaffe MB, et al. Canonical Wnt signalling activates TAZ through PP1A during osteogenic differentiation. Cell Death Differ. 2014;21(6):854-63.

23. Bu G, Lu W, Liu CC, Selander K, Yoneda T, Hall C, et al. Breast cancerderived Dickkopf1 inhibits osteoblast differentiation and osteoprotegerin expression: implication for breast cancer osteolytic bone metastases. Int J Cancer. 2008;123(5):1034-42.

24. Malhotra S, Baba Y, Garrett KP, Staal FJ, Gerstein R, Kincade PW. Contrasting responses of lymphoid progenitors to canonical and noncanonical Wnt signals. J Immunol. 2008;181(6):3955-64.

25. Kawaguchi-Ihara N, Murohashi I, Nara N, Tohda S. Promotion of the selfrenewal capacity of human acute leukemia cells by Wnt3A. Anticancer Res. 2008;28(5A):2701-4.

26. Zou C, Chou BK, Dowey SN, Tsang K, Huang X, Liu CF, et al. Efficient derivation and genetic modifications of human pluripotent stem cells on engineered human feeder cell lines. Stem Cells Dev. 2012;21(12):2298-311.

27. Vijayaragavan K, Szabo E, Bosse M, Ramos-Mejia V, Moon RT, Bhatia M. Noncanonical Wnt signaling orchestrates early developmental events toward hematopoietic cell fate from human embryonic stem cells. Cell Stem Cell. 2009;4(3):248-62.

28. Golestaneh N, Beauchamp E, Fallen S, Kokkinaki M, Uren A, Dym M. Wnt signaling promotes proliferation and stemness regulation of spermatogonial stem/progenitor cells. Reproduction. 2009;138(1):151-62.

29. Doubravska L, Simova S, Cermak L, Valenta T, Korinek V, Andera L. Wntexpressing rat embryonic fibroblasts suppress Apo2L/TRAlL-induced apoptosis of human leukemia cells. Apoptosis. 2008;13(4):573-87.

30. Dosen G, Tenstad E, Nygren MK, Stubberud H, Funderud S, Rian E. Wnt expression and canonical Wnt signaling in human bone marrow $B$ lymphopoiesis. BMC Immunol. 2006;7:13.

31. Trowbridge JJ, Guezguez B, Moon RT, Bhatia M. Wnt3a activates dormant c-Kit(-) bone marrow-derived cells with short-term multilineage hematopoietic reconstitution capacity. Stem Cells. 2010;28(8):1379-89. 
32. Nakamura T, Sano M, Songyang Z, Schneider MD. A Wnt- and betacatenin-dependent pathway for mammalian cardiac myogenesis. Proc Natl Acad Sci USA. 2003;100(10):5834-9.

33. Petropoulos H, Skerjanc IS. Beta-catenin is essential and sufficient for skeletal myogenesis in P19 cells. J Biol Chem. 2002;277(18):15393-9.

34. Greer YE, Fields AP, Brown AM, Rubin JS. Atypical protein kinase Ciota is required for Wnt3a-dependent neurite outgrowth and binds to phosphorylated dishevelled 2. J Biol Chem. 2013;288(13):9438-46.

35. Jr Dunty WC, Biris KK, Chalamalasetty RB, Taketo MM, Lewandoski M, Yamaguchi TP. Wnt3a/beta-catenin signaling controls posterior body development by coordinating mesoderm formation and segmentation. Development. 2008;135(1):85-94.

36. Rachner TD, Gobel A, Thiele S, Rauner M, Benad-Mehner P, Hadji P, et al. Dickkopf-1 is regulated by the mevalonate pathway in breast cancer. Breast Cancer Res. 2014;16(1):R20.

37. Deng ZB, Zhuang X, Ju S, Xiang X, Mu J, Wang Q, et al. Intestinal mucusderived nanoparticle-mediated activation of Wnt/beta-catenin signaling plays a role in induction of liver natural killer T cell anergy in mice. Hepatology. 2013;57(3):1250-61.

38. Wang Y, Dong J, Li D, Lai L, Siwko S, Li Y, et al. Lgr4 regulates mammary gland development and stem cell activity through the pluripotency transcription factor Sox2. Stem Cells. 2013;31(9):1921-31.

39. Pennisi A, Ling W, Li X, Khan S Jr, Shaughnessy JD, Barlogie B, et al. The ephrinB2/EphB4 axis is dysregulated in osteoprogenitors from myeloma patients and its activation affects myeloma bone disease and tumor growth. Blood. 2009;114(9):1803-12.

40. Aoyama K, Delaney C, Varnum-Finney B, Kohn AD, Moon RT, Bernstein ID. The interaction of the Wnt and Notch pathways modulates natural killer versus T cell differentiation. Stem Cells. 2007;25(10):2488-97.

41. You J, Nguyen AV, Albers CG, Lin F, Holcombe RF. Wnt pathwayrelated gene expression in inflammatory bowel disease. Dig Dis Sci. 2008;53(4):1013-9.

42. Planutis K, Planutiene M, Nguyen AV, Moyer MP, Holcombe RF. Invasive colon cancer, but not non-invasive adenomas induce a gradient effect of Wnt pathway receptor frizzled 1 (Fz1) expression in the tumor microenvironment. J Transl Med. 2013;11:50

43. Takei Y, Takigahira M, Mihara K, Tarumi Y, Yanagihara K. The metastasisassociated microRNA miR-516a-3p is a novel therapeutic target for inhibiting peritoneal dissemination of human scirrhous gastric cancer. Cancer Res. 2011:71(4):1442-53.

44. Bonci D, Coppola V, Musumeci M, Addario A, Giuffrida R, Memeo L, et al. The miR-15a-miR-16-1 cluster controls prostate cancer by targeting multiple oncogenic activities. Nat Med. 2008;14(11):1271-7.

45. Yan L, Della CL, Powell KL, Shen J, Thames H, Aldaz CM, et al. Activation of the canonical Wnt/beta-catenin pathway in ATF3-induced mammary tumors. PLoS One. 2011;6(1):e16515.

46. Benhaj K, Akcali KC, Ozturk M. Redundant expression of canonical Wnt ligands in human breast cancer cell lines. Oncol Rep. 2006;15(3):701-7.

47. Andrade FP, Letra A, Cramer A, Prasad JL, Garlet GP, Vieira AR, et al. Insights from studies with oral cleft genes suggest associations between WNT-pathway genes and risk of oral cancer. J Dent Res. 2011;90(6):740-6.

48. Kaur N, Chettiar S, Rathod S, Rath P, Muzumdar D, Shaikh ML, et al. Wnt3a mediated activation of Wnt/beta-catenin signaling promotes tumor progression in glioblastoma. Mol Cell Neurosci. 2013;54:44-57.

49. Katoh M. Regulation of WNT3 and WNT3A mRNAs in human cancer cell lines NT2, MCF-7, and MKN45. Int J Oncol. 2002;20(2):373-7.

50. Dean CH, Miller LA, Smith AN, Dufort D, Lang RA, Niswander LA. Canonical Wnt signaling negatively regulates branching morphogenesis of the lung and lacrimal gland. Dev Biol. 2005;286(1):270-86.

51. Thiago LS, Costa ES, Lopes DV, Otazu IB, Nowill AE, Mendes FA, et al. The Wnt signaling pathway regulates Nalm-16 b-cell precursor acute lymphoblastic leukemic cell line survival and etoposide resistance. Biomed Pharmacother. 2010;64(1):63-72.

52. Nygren MK, Dosen G, Hystad ME, Stubberud H, Funderud S, Rian E. Wnt3A activates canonical Wnt signalling in acute lymphoblastic leukaemia (ALL) cells and inhibits the proliferation of B-ALL cell lines. $\mathrm{Br}$ J Haematol. 2007;136(3):400-13.

53. Zimmerman ZF, Kulikauskas RM, Bomsztyk K, Moon RT, Chien AJ. Activation of Wnt/beta-catenin signaling increases apoptosis in melanoma cells treated with trail. PLoS One. 2013;8(7):e69593.
54. Annavarapu SR, Cialfi S, Dominici C, Kokai GK, Uccini S, Ceccarelli S, et al. Characterization of Wnt/beta-catenin signaling in rhabdomyosarcoma. Lab Invest. 2013;93(10):1090-9.

55. Quan MF, Xiao LH, Liu ZH, Guo H, Ren KQ, Liu F, et al. 8-bromo-7-methoxychrysin inhibits properties of liver cancer stem cells via downregulation of beta-catenin. World J Gastroenterol. 2013;19(43):7680-95.

56. Khan NI, Bradstock KF, Bendall LJ. Activation of Wnt/beta-catenin pathway mediates growth and survival in B-cell progenitor acute lymphoblastic leukaemia. Br J Haematol. 2007;138(3):338-48.

57. Bjorklund CC, Ma W, Wang ZQ, Davis RE, Kuhn DJ, Kornblau SM, et al. Evidence of a role for activation of Wnt/beta-catenin signaling in the resistance of plasma cells to lenalidomide. J Biol Chem. 2011;286(13):11009-20.

58. Fox SA, Richards AK, Kusumah I, Perumal V, Bolitho EM, Mutsaers SE, et al. Expression profile and function of Wnt signaling mechanisms in malignant mesothelioma cells. Biochem Biophys Res Commun. 2013;440(1):82-7.

59. Wang SH, Li N, Wei Y, Li QR, Yu ZP. beta-catenin deacetylation is essentia for WNT-induced proliferation of breast cancer cells. Mol Med Rep. 2014;9(3):973-8.

60. Akaboshi S, Watanabe S, Hino Y, Sekita Y, Xi Y, Araki K, et al. HMGA1 is induced by Wnt/beta-catenin pathway and maintains cell proliferation in gastric cancer. Am J Pathol. 2009;175(4):1675-85.

61. Song KS, Jing K, Kim JS, Yun EJ, Shin S, Seo KS, et al. Omega-3-polyunsaturated fatty acids suppress pancreatic cancer cell growth in vitro and in vivo via downregulation of Wnt/Beta-catenin signaling. Pancreatology. 2011;11(6):574-84.

62. Li X, Placencio V, Iturregui JM, Uwamariya C, Sharif-Afshar AR, Koyama T, et al. Prostate tumor progression is mediated by a paracrine TGF-beta/ Wnt3a signaling axis. Oncogene. 2008;27(56):7118-30.

63. Zhang Q, Bai X, Chen W, Ma T, Hu Q, Liang C, et al. Wnt/beta-catenin signaling enhances hypoxia-induced epithelial-mesenchymal transition in hepatocellular carcinoma via crosstalk with hif-1alpha signaling. Carcinogenesis. 2013;34(5):962-73.

64. Kim H, Seo EM, Sharma AR, Ganbold B, Park J, Sharma G, et al. Regulation of Wnt signaling activity for growth suppression induced by quercetin in 4T1 murine mammary cancer cells. Int J Oncol. 2013:43(4):1319-25

65. Shen DY, Zhang W, Zeng X, Liu CQ. Inhibition of Wnt/beta-catenin signaling downregulates $P$-glycoprotein and reverses multi-drug resistance of cholangiocarcinoma. Cancer Sci. 2013;104(10):1303-8.

66. Qiang YW, Endo Y, Rubin JS, Rudikoff S. Wnt signaling in B-cell neoplasia. Oncogene. 2003;22(10):1536-45.

67. Raz DJ, Ray MR, Kim JY, He B, Taron M, Skrzypski M, et al. A multigene assay is prognostic of survival in patients with early-stage lung adenocarcinoma. Clin Cancer Res. 2008:14(17):5565-70.

68. Biechele TL, Camp ND, Fass DM, Kulikauskas RM, Robin NC, White BD, et al. Chemical-genetic screen identifies riluzole as an enhancer of Wnt/ beta-catenin signaling in melanoma. Chem Biol. 2010;17(11):1177-82.

69. Liu J, Ding X, Tang J, Cao Y, Hu P, Zhou F, et al. Enhancement of canonical Wnt/beta-catenin signaling activity by HCV core protein promotes cell growth of hepatocellular carcinoma cells. PLoS One. 2011:6(11):e27496.

70. Green JL, La J, Yum KW, Desai P, Rodewald LW, Zhang X, et al. Paracrine Wnt signaling both promotes and inhibits human breast tumor growth. Proc Natl Acad Sci USA. 2013;110(17):6991-6.

71. Wei Y, Shen N, Wang Z, Yang G, Yi B, Yang N, et al. Sorafenib sensitizes hepatocellular carcinoma cell to cisplatin via suppression of Wnt/betacatenin signaling. Mol Cell Biochem. 2013;381(1-2):139-44.

72. Qiang YW, Chen Y, Stephens O, Brown N, Chen B, Epstein J, et al. Myeloma-derived Dickkopf-1 disrupts Wnt-regulated osteoprotegerin and RANKL production by osteoblasts: a potential mechanism underlying osteolytic bone lesions in multiple myeloma. Blood. 2008;112(1):196-207.

73. Noh KT, Park YM, Cho SG, Choi EJ. GSK-3beta-induced ASK1 stabilization is crucial in LPS-induced endotoxin shock. Exp Cell Res. 2011;317(12):1663-8.

74. Bisson I, Prowse DM. WNT signaling regulates self-renewal and differentiation of prostate cancer cells with stem cell characteristics. Cell Res. 2009;19(6):683-97. 
75. Zhang N, Wei P, Gong A, Chiu WT, Lee HT, Colman H, et al. FoxM1 promotes beta-catenin nuclear localization and controls Wnt target-gene expression and glioma tumorigenesis. Cancer Cell. 2011;20(4):427-42.

76. Smartt HJ, Greenhough A, Ordonez-Moran P, Talero E, Cherry CA, Wallam CA, et al. beta-catenin represses expression of the tumour suppressor 15-prostaglandin dehydrogenase in the normal intestinal epithelium and colorectal tumour cells. Gut. 2012;61(9):1306-14.

77. Kang DW, Lee SH, Yoon JW, Park WS, Choi KY, Min DS. Phospholipase D1 drives a positive feedback loop to reinforce the Wnt/beta-catenin/TCF signaling axis. Cancer Res. 2010;70(10):4233-42.

78. Kang DW, Min DS. Positive feedback regulation between phospholipase $\mathrm{D}$ and Wnt signaling promotes Wnt-driven anchorage-independent growth of colorectal cancer cells. PLoS One. 2010;5(8):e12109.

79. Dai J, Hall CL, Escara-Wilke J, Mizokami A, Keller JM, Keller ET. Prostate cancer induces bone metastasis through Wnt-induced bone morphogenetic protein-dependent and independent mechanisms. Cancer Res. 2008;68(14):5785-94.

80. Lai YH, Cheng J, Cheng D, Feasel ME, Beste KD, Peng J, et al. SOX4 interacts with plakoglobin in a Wnt3a-dependent manner in prostate cancer cells. BMC Cell Biol. 2011;12:50.

81. Schweizer L, Rizzo CA, Spires TE, Platero JS, Wu Q, Lin TA, et al. The androgen receptor can signal through Wnt/beta-Catenin in prostate cancer cells as an adaptation mechanism to castration levels of androgens. BMC Cell Biol. 2008;9:4

82. Verras M, Brown J, Li X, Nusse R, Sun Z. Wnt3a growth factor induces androgen receptor-mediated transcription and enhances cell growth in human prostate cancer cells. Cancer Res. 2004;64(24):8860-6.

83. Lee MA, Park JH, Rhyu SY, Oh ST, Kang WK, Kim HN. Wnt3a expression is associated with MMP-9 expression in primary tumor and metastatic site in recurrent or stage IV colorectal cancer. BMC Cancer. 2014;14:125.

84. Lamb R, Ablett MP, Spence K, Landberg G, Sims AH, Clarke RB. Wnt pathway activity in breast cancer sub-types and stem-like cells. PLoS One. 2013:8(7):e67811.

85. Lai JP, Oseini AM, Moser CD, Yu C, Elsawa SF, Hu C, et al. The oncogenic effect of sulfatase 2 in human hepatocellular carcinoma is mediated in part by glypican 3-dependent Wnt activation. Hepatology. 2010;52(5):1680-9.

86. Yang Y, Jiao L, Hou J, Xu C, Wang L, Yu Y, et al. Dishevelled-2 silencing reduces androgen-dependent prostate tumor cell proliferation and migration and expression of Wnt-3a and matrix metalloproteinases. Mol Biol Rep. 2013;40(7):4241-50.

87. Li C, Chen H, Hu L, Xing Y, Sasaki T, Villosis MF, et al. Ror2 modulates the canonical Wnt signaling in lung epithelial cells through cooperation with Fzd2. BMC Mol Biol. 2008;9:11.

88. Finlayson AE, Freeman KW. A cell motility screen reveals role for MARCKS-related protein in adherens junction formation and tumorigenesis. PLoS One. 2009;4(11):e7833.

89. Quelard D, Lavergne E, Hendaoui I, Elamaa H, Tiirola U, Heljasvaara R, et al. A cryptic frizzled module in cell surface collagen 18 inhibits Wnt/ beta-catenin signaling. PLoS One. 2008;3(4):e1878.

90. Sottnik JL, Hall CL, Zhang J, Keller ET. Wnt and Wnt inhibitors in bone metastasis. Bonekey Rep. 2012;1:101.

91. Gavriatopoulou M, Dimopoulos MA, Christoulas D, Migkou M, lakovaki M, Gkotzamanidou M, et al. Dickkopf-1: a suitable target for the management of myeloma bone disease. Expert Opin Ther Targets. 2009;13(7):839-48.

92. Qiang YW, Barlogie B, Rudikoff S Jr, Shaughnessy JD. Dkk1-induced inhibition of Wnt signaling in osteoblast differentiation is an underlying mechanism of bone loss in multiple myeloma. Bone. 2008;42(4):669-80.

93. Yuan JB, Yang LY, Tang ZY, Zu XB, Qi L. Down-regulation of EZH2 by RNA interference inhibits proliferation and invasion of ACHN cells via the Wnt/beta-catenin pathway. Asian Pac J Cancer Prev. 2012;13(12):6197-201

94. Conrad W, Major MB, Cleary MA, Ferrer M, Roberts B, Marine S, et al. FAM129B is a novel regulator of Wnt/beta-catenin signal transduction in melanoma cells. F1000Research. 2013;2:134.

95. Fonar Y, Gutkovich YE, Root H, Malyarova A, Aamar E, Golubovskaya VM, et al. Focal adhesion kinase protein regulates Wnt3a gene expression to control cell fate specification in the developing neural plate. Mol Biol Cell. 2011;22(13):2409-21.
96. Gao W, Kim H, Feng M, Phung Y, Xavier CP, Rubin JS, et al. Inactivation of Wnt signaling by a human antibody that recognizes the heparan sulfate chains of glypican-3 for liver cancer therapy. Hepatology. 2014;60(2):576-87.

97. Willis CM, Kluppel M. Inhibition by chondroitin sulfate E can specify functional Wnt/beta-catenin signaling thresholds in NIH3T3 fibroblasts. J Biol Chem. 2012;287(44):37042-56.

98. Hendaoui I, Lavergne E, Lee HS, Hong SH, Kim HZ, Parent C, et al. Inhibition of Wnt/beta-catenin signaling by a soluble collagen-derived frizzled domain interacting with Wnt3a and the receptors frizzled 1 and 8. PLoS One. 2012;7(1):e30601.

99. Zhang J, Yang Z, Li P, Bledsoe G, Chao L, Chao J. Kallistatin antagonizes Wnt/beta-catenin signaling and cancer cell motility via binding to low-density lipoprotein receptor-related protein 6. Mol Cell Biochem. 2013;379(1-2):295-301.

100. Zhang W, Zhang H, Wang N, Zhao C, Deng F, Wu N, et al. Modulation of beta-catenin signaling by the inhibitors of MAP kinase, tyrosine kinase, and PI3-kinase pathways. Int J Med Sci. 2013;10(13):1888-98.

101. Turm H, Maoz M, Katz V, Yin YJ, Offermanns S, Bar-Shavit R. Proteaseactivated receptor-1 (PAR1) acts via a novel Galpha13-dishevelled axis to stabilize beta-catenin levels. J Biol Chem. 2010;285(20):15137-48.

102. James RG, Bosch KA, Kulikauskas RM, Yang PT, Robin NC, Toroni RA, et al. Protein kinase PKN1 represses Wnt/beta-catenin signaling in human melanoma cells. J Biol Chem. 2013;288(48):34658-70.

103. Deng YZ, Yao F, Li JJ, Mao ZF, Hu PT, Long LY, et al. RACK1 suppresses gastric tumorigenesis by stabilizing the beta-catenin destruction complex. Gastroenterology. 2012;142(4):812-823.e815.

104. Feigin ME, Malbon CC. RGS19 regulates Wnt-beta-catenin signaling through inactivation of Galpha(o). J Cell Sci. 2007;120(Pt 19):3404-14.

105. Lin C, Lu W, Zhang W, Londono-Joshi Al, Buchsbaum DJ, Bu G, et al. The C-terminal region Mesd peptide mimics full-length Mesd and acts as an inhibitor of Wnt/beta-catenin signaling in cancer cells. PLoS One. 2013;8(2):e58102

106. Wang W, Liu H, Wang S, Hao X, Li L. A diterpenoid derivative 15-oxospiramilactone inhibits Wnt/beta-catenin signaling and colon cancer cell tumorigenesis. Cell Res. 2011;21(5):730-40.

107. Ko BS, Lu YJ, Yao WL, Liu TA, Tzean SS, Shen TL, et al. Cordycepin regulates GSK-3beta/beta-catenin signaling in human leukemia cells. PLoS One. 2013;8(9):e76320

108. Chuang KA, Lieu CH, Tsai WJ, Wu MH, Chen YC, Liao JF, et al. Evaluation of anti-Wnt/beta-catenin signaling agents by PGL4-TOP transfected stable cells with a luciferase reporter system. Braz J Med Biol Res. 2010;43(10):931-41.

109. Park S, Gwak J, Cho M, Song T, Won J, Kim DE, et al. Hexachlorophene inhibits Wnt/beta-catenin pathway by promoting Siah-mediated betacatenin degradation. Mol Pharmacol. 2006;70(3):960-6.

110. Ryu MJ, Cho M, Song JY, Yun YS, Choi IW, Kim DE, et al. Natural derivatives of curcumin attenuate the Wnt/beta-catenin pathway through down-regulation of the transcriptional coactivator p300. Biochem Biophys Res Commun. 2008;377(4):1304-8.

111. Lu W, Lin C, Roberts MJ, Waud WR, Piazza GA, Li Y. Niclosamide suppresses cancer cell growth by inducing Wnt co-receptor LRP6 degradation and inhibiting the Wnt/beta-catenin pathway. PLoS One. 2011;6(12):e29290.

112. Lu W, Lin C, King TD, Chen H, Reynolds RC, Li Y. Silibinin inhibits Wnt/beta-catenin signaling by suppressing Wnt co-receptor LRP6 expression in human prostate and breast cancer cells. Cell Signal. 2012;24(12):2291-6.

113. Takamatsu A, Ohkawara B, Ito M, Masuda A, Sakai T, Ishiguro N, et al. Verapamil protects against cartilage degradation in osteoarthritis by inhibiting Wnt/beta-catenin signaling. PLoS One. 2014;9(3):e92699.

114. Kim S, Chun SY, Lee DH, Lee KS, Nam KS. Mineral-enriched deep-sea water inhibits the metastatic potential of human breast cancer cell lines. Int J Oncol. 2013:43(5):1691-700.

115. Katoh M. Regulation of WNT signaling molecules by retinoic acid during neuronal differentiation in NT2 cells: threshold model of WNT action (review). Int J Mol Med. 2002;10(6):683-7

116. Kang YJ, Park HJ, Chung HJ, Min HY, Park EJ, Lee MA, et al. Wnt/betacatenin signaling mediates the antitumor activity of magnolol in colorectal cancer cells. Mol Pharmacol. 2012;82(2):168-77. 